\title{
Evaluation of dosing guidelines for use of controlled-release codeine in chronic noncancer pain
}

\author{
Alan Russell $M D^{1}$, C Peter N Watson $\mathrm{MD}^{2}$, Alexander J Clark $\mathrm{MD}^{3}$, William Arkinstall $\mathrm{MD}^{4}$, Dwight Moulin $\mathrm{MD}^{5}$, \\ Helen Hays $\mathrm{MD}^{6}$, John Eisenhoffer MD MSc${ }^{7}$, Patricia Quigley MSc7, Zoltan Harsanyi MBA ${ }^{7}$, Andrew Darke $\mathrm{PhD}^{7}$
}

\begin{abstract}
A Russell, CPN Watson, AJ Clark, et al. Evaluation of dosing guidelines for use of controlled-release codeine in chronic noncancer pain. Pain Res Manage 2003;8(3):143-148.
\end{abstract}

OBJECTIVE: The clinical utility of guidelines for conversion of patients from a combination analgesic preparation of acetaminophen $300 \mathrm{mg}$ plus codeine $30 \mathrm{mg}$ every $4 \mathrm{~h}$ to $6 \mathrm{~h}$ as needed to scheduled controlled-release $(\mathrm{CR})$ codeine every $12 \mathrm{~h}$ was evaluated.

METHODS: Adult patients with chronic noncancer pain underwent a two-week evaluation on acetaminophen plus codeine, followed by eight weeks of treatment with CR codeine. Patients taking four to six tablets of acetaminophen plus codeine per day were transferred to $50 \mathrm{mg}$ CR codeine every $12 \mathrm{~h}$; those on seven to nine tablets were transferred to $100 \mathrm{mg}$ every $12 \mathrm{~h}$; those on 10 to 12 tablets were transferred to $150 \mathrm{mg}$ every $12 \mathrm{~h}$; and those on greater than 12 tablets were transferred to $200 \mathrm{mg}$ every $12 \mathrm{~h}$. Subsequent dose adjustments were permitted. Acetaminophen ( $325 \mathrm{mg}$ ) was available for rescue. Pain intensity (five-point categorical and $100 \mathrm{~mm}$ visual analog scale), pain related disability, adverse events and acceptability were assessed.

RESULTS: Of the 140 patients enrolled, 95 completed eight weeks of treatment with CR codeine. During month 1 and month 2, the mean CR codeine daily doses were $295.7 \pm 119.1 \mathrm{mg}$ and $390.3 \pm 163.4 \mathrm{mg}$, respectively. Pain scores during both CR codeine month 1 and 2 were significantly lower than on acetaminophen plus codeine $(53.6 \pm 20.9 \mathrm{~mm}$ and $49.7 \pm 23.7 \mathrm{~mm}$ versus $59.6 \pm 17.5 \mathrm{~mm} ; \mathrm{P}=0.0003, \mathrm{P}=0.0001$, respectively). CR codeine treatment was rated as moderately or highly acceptable by $82 \%$ of patients compared with $50 \%$ for acetaminophen plus codeine $(\mathrm{P}=0.001)$. Only seven patients $(5.9 \%)$ discontinued CR codeine treatment because of adverse events.

CONCLUSION: The results confirm the safety, efficacy and patient acceptability of the initial conversion and maintenance dosing recommendations for CR codeine from a combination opioid/nonopioid analgesic.

Key words: Chronic pain; Controlled-release codeine

\section{L'évaluation des lignes directrices sur les doses d'utilisation de codéine à libération contrôlée en cas de douleur non cancéreuse chronique}

OBJECTIF : Est évaluée l'utilité clinique des lignes directrices pour faire passer le traitement des patients d'une association de préparation analgésique de $300 \mathrm{mg}$ d'acétaminophène et de $30 \mathrm{mg}$ de codéine toutes les quatre à six heures au besoin à de la codéine à libération contrôlée (LC) programmée toutes les 12 heures.

MÉTHODOLOGIE : Des patients adultes souffrant de douleur non cancéreuse chronique ont subi une évaluation de deux semaines pendant qu'ils prenaient de l'acétaminophène associée à de la codéine, suivie par un traitement de huit semaines à la codéine à LC. Des patients prenant de quatre à six comprimés d'acétaminophène et de codéine par jour sont passés à $50 \mathrm{mg}$ de codéine à $\mathrm{LC}$ toutes les 12 heures, ceux qui en prenaient de sept à neuf, à $100 \mathrm{mg}$ toutes les 12 heures, ceux qui en prenaient de dix à 12 , à $150 \mathrm{mg}$ toutes les 12 heures et ceux qui en prenaient plus de 12 , à $200 \mathrm{mg}$ toutes les 12 heures. Des rajustements de la posologie étaient autorisés. Il était possible de prendre de l'acétaminophène $(325 \mathrm{mg}$ ) comme antidote électif. L'intensité de la douleur (échelle nominale de cinq points et échelle analogique visuelle de $100 \mathrm{mg}$ ), l'incapacité causée par la douleur, les événements indésirables et l'acceptabilité ont été évalués.

RÉSULTATS : Des 140 patients enrôlés, 95 ont terminé huit semaines de traitement à la codéine à LC. Pendant le premier et le deuxième mois, les doses quotidiennes moyennes de codéine à LC s'élevaient à 295,7×119,1 mg et à 390,3 $\pm 163,4 \mathrm{mg}$, respectivement. Les échelles de douleur pendant les premier et deuxième mois sous codéine à LC étaient beaucoup plus faibles que sous acétaminophène et codéine $(53,6 \pm 20,9 \mathrm{~mm}$ et $49,7 \pm 23,7 \mathrm{~mm}$ comparativement à 59,6 $\pm 17,5 \mathrm{~mm} ; \mathrm{P}=0,0003, \mathrm{P}=0,0001$, respectivement). Le traitement à la codéine à LC était évalué comme modérément ou hautement acceptable par $82 \%$ des patients par rapport à $50 \%$ de ceux qui prenaient de l'acétaminophène associée à de la codéine $(\mathrm{P}=0,001)$. Seulement sept patients $(5,9 \%)$ ont mis fin au traitement à la codéine à LC en raison d'événements indésirables.

CONCLUSION : Les résultats confirment l'innocuité, l'efficacité et l'acceptabilité par le patient de la conversion initiale et des recommandations relatives à une dose d'entretien de codéine à LC en remplacement d'une association d'analgésiques opioïdes et non opioïdes.

$(2-7)$, codeine is generally recommended for mild to moderate pain (8) but is usually used in combination with acetaminophen in immediate-release formulations. Controlled-release (CR) codeine dosed every $12 \mathrm{~h}$ provides an equivalent extent of absorption compared with immediate release codeine dosed
The goal of analgesic therapy is to achieve continuous sup1 pression of pain by administering the next dose before the effects of the previous dose have worn off (1). While there are controlled-release formulations of opioids that meet this therapeutic objective for the treatment of severe chronic pain
${ }^{1}$ William Osler Health Centre, Brampton, Ontario; ${ }^{2}$ University of Toronto, Toronto, Ontario; ${ }^{3}$ Queen Elizabeth II Health Services Centre,
Halifax, Nova Scotia; ${ }^{4}$ Kelowna General Hospital, Kelowna, British Columbia; ${ }^{5}$ London Health Science Centre, London, Ontario;

${ }^{6}$ University of Alberta Hospital, Edmonton, Alberta; ${ }^{7}$ Purdue Pharma, Pickering, Ontario

Correspondence and reprints: Dr Andrew C Darke, Purdue Pharma, 575 Granite Court, Pickering, Ontario L1W 3 W8.

Telephone 905-420-6400,fax 905-420-2503, e-mail dr_Andrew_Darke@pfcan.com 
TABLE 1

Conversion from acetaminophen plus codeine phosphate combinations to controlled-release codeine

\begin{tabular}{lcc}
\hline $\begin{array}{l}\text { Number of } \mathbf{3 0} \text { mg codeine } \\
\text { combination tablets } \\
\text { per day }\end{array}$ & $\begin{array}{c}\text { Initial dose of } \\
\text { CR codeine } \\
\text { (mg every } \mathbf{~} \mathbf{~ h )}\end{array}$ & $\begin{array}{c}\text { Maintenance dose of } \\
\text { CR codeine } \\
\text { (mg every } \mathbf{~ 1 2 ~} \mathbf{~} \text { ) }\end{array}$ \\
\hline $4-6$ & 50 & 100 \\
$7-9$ & 100 & 150 \\
$10-12$ & 150 & 200 \\
$>12$ & 200 & 300 \\
\hline
\end{tabular}

Data from reference 30. CR Controlled-release

every $4 \mathrm{~h}$ to $6 \mathrm{~h}$ (9), and has the advantage of less frequent scheduled dosing and improved pain control without the limitations of fixed-dose combinations of short-acting opioids with nonsteroidal anti-inflammatory drugs or acetaminophen $(10,11)$.

Fixed-dose combinations of codeine-acetaminophencaffeine have an upper dose limit imposed by acetaminophen, which prevents titration of patients to higher opioid doses. Also, chronic use of high doses of acetaminophen (greater than $5000 \mathrm{mg}$ daily) has been associated with hepatotoxicity and kidney damage $(12,13)$ and the caffeine component may cause insomnia resulting in increased pain.

CR codeine has also been shown to result in significantly lower pain intensity scores, daily rescue analgesic consumption and Pain Disability Index (PDI) scores when compared with placebo in patients with cancer (14), chronic nonmalignant pain of varying etiology (11) and osteoarthritis (15), and has been compared with acetaminophen plus codeine in chronic back pain (16).

A dose response for CR codeine was demonstrated with both single doses and at steady state in a comparison of CR codeine and acetaminophen plus codeine in patients with cancer pain. CR codeine at approximately $150 \mathrm{mg}$ every $12 \mathrm{~h}$ was shown to be equivalent in effect to acetaminophen plus codeine 600/60 mg every $6 \mathrm{~h}$, with similar side effects (10). Arkinstall et al (11) used this equianalgesic dose ratio to convert patients with chronic nonmalignant pain to $\mathrm{CR}$ codeine in a placebo-controlled crossover study. In the placebo phase of this study, patients consumed approximately two tablets less per day of the acetaminophen plus codeine combination than they reported using before enrollment into the study. This suggests that an initial conversion dose of CR codeine, based on a lower dose of acetaminophen plus codeine than that reported in the patient's history, may provide an acceptable level of analgesia while minimizing the risk of early adverse effects.

This study evaluated the safety and effectiveness of proposed guidelines for the initial conversion dose and subsequent maintenance dose of CR codeine in patients currently receiving an analgesic combination of acetaminophen plus codeine.

\section{Patients}

\section{METHODS}

Male or nonpregnant female patients over 18 years of age, with chronic pain of noncancer origin, who were mentally and physically competent to provide consent, participated in this open-label evaluation. Patients were excluded if they had intractable nausea or vomiting, a clinically significant intoler- ance to acetaminophen or any opioid, a history of drug abuse or unstable renal function, or other serious respiratory, cardiovascular, gastrointestinal or central nervous system conditions. The study protocol and informed consent form were reviewed and approved by a research ethics board at each of the eight centres in Canada, and all patients gave written informed consent before participating in the study.

\section{Medications}

Patients underwent a minimum two week prospective evaluation on acetaminophen plus codeine (Tylenol No 3, McNeil Pharmaceuticals, Don Mills, Ontario, Canada), before initiating treatment with CR codeine (Codeine Contin, Purdue Pharma, Pickering, Ontario, Canada) with plain acetaminophen for rescue (Tylenol, McNeil Pharmaceuticals, Don Mills, Ontario, Canada). The initial dose of CR codeine was based on the average daily acetaminophen plus codeine dose during the two week baseline evaluation, using the guidelines listed in Table 1. The dose was increased from the initial dose to the maintenance dose if pain was not adequately controlled (ie, greater than mild on a five-point categorical scale and/or the patient required four or more tablets of acetaminophen per day for breakthrough pain).

CR codeine was taken every $12 \mathrm{~h}$ at 08:00 and 20:00, and patients were given a supply of acetaminophen to be used at a dose of one to two tablets every $4 \mathrm{~h}$ as required for breakthrough pain. The maximum daily dose of acetaminophen was not to exceed 12 tablets. No other opioids were permitted during the study; however, patients were allowed to continue stable doses of other analgesics (nonsteroidal anti-inflammatory drugs, corticosteroids, tricyclic antidepressants, anticonvulsants or antiarrhythmics) provided their dose had not changed for at least 14 days preceding the study. Common opioid side effects, such as nausea and constipation, were managed with appropriate drugs.

\section{Study design}

This was an open-label evaluation of guidelines for the initiation of CR codeine $50 \mathrm{mg}, 100 \mathrm{mg}, 150 \mathrm{mg}$ or $200 \mathrm{mg}$ every $12 \mathrm{~h}$ in patients with chronic noncancer pain, with respect to clinical effectiveness (pain intensity and rescue analgesic use), pain-related disability, pain and sleep, safety, and overall patient and investigator acceptability of treatment.

Treatment lasted eight weeks and patients returned to the clinic for evaluation every four weeks (28 to 32 days). Patients were contacted weekly to assess the need for dose adjustments in relation to the level of pain control and the occurrence of adverse effects. Patients who successfully completed the study were eligible for an additional six month, long term open-label treatment period with CR codeine.

Analgesic efficacy was assessed daily at 08:00 and 20:00 using a five-point categorical pain intensity scale $(0=$ none, 1 =mild, 2 =moderate, 3 =severe, 4 =excruciating) and a $100 \mathrm{~mm}$ visual analog scale (VAS), bounded on the left by "no pain" and on the right by "excruciating pain".

Patients rated the overall acceptability of treatment and their pain-related disability at the baseline visit (before the start of acetaminophen plus codeine), the postbaseline visit (at the start of CR codeine treatment) and at the four and eight 
TABLE 2

Patient disposition

\begin{tabular}{lc}
\hline Cause of pain & Percentage of patients \\
\hline Injury & 29.5 \\
Arthritis & 16.8 \\
Motor vehicle accident & 15.8 \\
Surgery & 14.7 \\
Degenerative disk disease & 7.4 \\
Neuropathy & 6.3 \\
Fibromyalgia & 3.2 \\
Headache & 2.1 \\
Other & 18.9
\end{tabular}

week visits (while receiving CR codeine). Investigators also rated the overall acceptability of treatment at the above time points. Acceptability of treatment was assessed by asking, "How would you rate the acceptability of the treatment based on the degree of pain relief and the tolerability of any side effects?" $(0=$ not at all acceptable; $1=$ slightly acceptable; $2=$ moderately acceptable; $3=$ highly acceptable). The PDI $(17,18)$ consists of seven disability subscales, each representing a different area of every day functioning: 1) family/home responsibilities, 2) recreation, 3) social activities, 4) occupation, 5) sexual behaviour, 6) self-care and 7) life-support activity. Each scale is graded from 0 to 10 , where $0=$ no disability and $10=$ total disability. An overall disability score was determined by summing the numerical ratings of the seven disability scales (range: 0 to 70 ).

At each visit, the impact of pain on sleep was assessed with a $100 \mathrm{~mm}$ VAS (anchors: never to always) which included questions like "How often have you had trouble falling asleep because of pain?", "How often have you needed medication to fall asleep?", "How often have you been awakened by pain during the night?", and "How often have you been awakened by pain in the morning?".

The occurrence and severity $(0=$ none, $1=$ mild, $2=$ moder ate, $3=$ severe) of any adverse events were assessed at each clinic visit using a nondirected adverse events questionnaire. Rescue acetaminophen use (date and time, and the number of tablets consumed) was recorded in the patient diary.

\section{RESULTS}

A total of 140 patients were enrolled in the study, of which 22 (16\%), $10(7 \%)$, and $13(9 \%)$ patients discontinued during treatment with acetaminophen plus codeine and during CR codeine month 1 (weeks 1 to 4 ) and month 2 (weeks 5 to 8 ) of the study, respectively. The reasons for withdrawal were: adverse events (14 patients), voluntary patient withdrawal (11 patients), patient noncompliance (6 patients) inadequate pain control (6 patients), other ( 5 patients) and protocol violation ( 3 patients). The distribution of reasons given for discontinuation did not vary dramatically across phases. Five per cent of patients withdrew during the acetaminophen plus codeine phase due to adverse events, whereas $2.5 \%$ and $4 \%$ of patients discontinued CR codeine treatment due to adverse events during month 1 and month 2, respectively. Itching, constipation, drowsiness, dry mouth, difficulty voiding, flu,
TABLE 3

Study doses

\begin{tabular}{lccc}
\hline & $\begin{array}{c}\text { Acetaminophen } \\
\text { plus codeine } \\
\text { treatment phase }\end{array}$ & $\begin{array}{c}\text { CR codeine } \\
\text { month 1 } \\
\text { (weeks 1-4) } \\
\text { treatment phase }\end{array}$ & $\begin{array}{c}\text { CR codeine } \\
\text { month 2 } \\
\text { (weeks 5-8) } \\
\text { treatment phase }\end{array}$ \\
\hline $\begin{array}{l}\text { Initial dose } \\
\begin{array}{l}\text { Mean daily dose } \\
\text { for period }\end{array}\end{array}$ & $8.3 \pm 3.3$ tablets & $221.5 \pm 114.0 \mathrm{mg}$ & $376.1 \pm 166.5 \mathrm{mg}$ \\
$\begin{array}{l}\text { Final daily dose } \\
\text { at end of period }\end{array}$ & $\mathrm{N} / \mathrm{A}$ & $360.0 \pm 151.9 \mathrm{mg}$ & $403.7 \pm 172.9 \mathrm{mg}$ \\
$\begin{array}{l}\text { Number of days of } \\
\text { treatment }\end{array}$ & $14.4 \pm 1.5$ & $27.9 \pm 3.2$ & $28.7 \pm 2.9$ \\
$\begin{array}{l}\text { Number of dose } \\
\text { changes }\end{array}$ & $\mathrm{N} / \mathrm{A}$ & $1.9 \pm 1.8$ & \\
\hline
\end{tabular}

Figures are mean $\pm S D$. CR Controlled-release; N/A Not available

TABLE 4

Distribution of controlled-release codeine doses

\section{Dose}

CR codeine

(mg/day)

\begin{tabular}{lccc}
\hline 50 & 0 & 1 & 0 \\
100 & 30 & 2 & 3 \\
150 & 0 & 0 & 1 \\
200 & 34 & 22 & 19 \\
300 & 16 & 23 & 15 \\
400 & 14 & 25 & 20 \\
500 & 0 & 6 & 10 \\
600 & 1 & 15 & 24 \\
700 & 0 & 1 & 1 \\
800 & 0 & 0 & 2 \\
Total & 95 & 95 & 95 \\
\hline
\end{tabular}

diarrhea, swollen feet, disorientation, nausea and vomiting were the reasons for early discontinuation of treatment.

Ninety-five patients (46 men, 49 women; mean age $47.7 \pm 12.1$ years) completed the eight week study and were evaluated for efficacy. The majority of patients had pain in the lower back (67 patients), followed by leg (57 patients), joint (50 patients) and shoulder (48 patients). Some patients had multiple sites and multiple causes of pain (Table 2). Most patients had steady pain (89 patients) and pain at rest (80 patients). Pain intensity and estimates of the benefits of their current medication did not differ as a function of site of pain. Sixty-one patients were taking acetaminophen plus codeine before enrollment and the mean duration of opioid use before the study was $5.9 \pm 5.5$ years.

The initial, mean daily and final doses, treatment duration and number of dose changes are listed in Table 3. The distribution of doses at weeks four and eight is shown in Table 4. The average time to the first dose increase was $8.6 \pm 6.5$ days and the maximum was 29 days $(n=79)$. Fourteen per cent of patients had no change in their dose throughout the study. Seventy-six patients $(80 \%)$ increased their dose by week 4 and 32 patients (33.7\%) increased their dose from week 4 to week 8. 


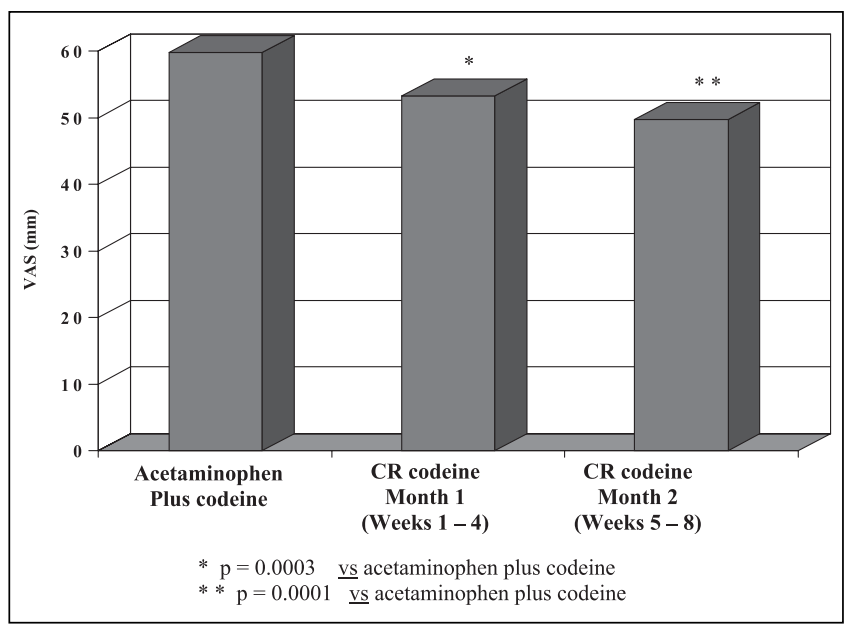

Figure 1) Pain intensity (100 mm VAS) measured daily during the two-week acetaminophen plus codeine phase and weeks one to four and five to eight CR codeine phases. CR Controlled-release; VAS Visual analog scale

\section{TABLE 5}

Comparison of pain intensities, pain disability index and rescue analgesic use

\begin{tabular}{lccc}
\hline & $\begin{array}{c}\text { Acetaminophen } \\
\text { plus } \\
\text { codeine } \\
(\mathbf{n}=\mathbf{9 5})\end{array}$ & $\begin{array}{c}\text { CR codeine } \\
\text { month1 } \\
\text { (weeks 1-4) } \\
(\mathbf{n}=95)\end{array}$ & $\begin{array}{c}\text { CR codeine } \\
\text { month2 } \\
\text { (weeks 5-8) } \\
\text { (n= 95) }\end{array}$ \\
\hline Pain intensity & $2.5 \pm 0.57$ & $2.3 \pm 0.73^{* *}$ & $2.2 \pm 0.79 *$ \\
categorical $(0-4)$ & * & $36.4 \pm 17.49^{* *}$ & $36.6 \pm 18.38^{* *}$ \\
Total PDI score & $40.1 \pm 16.24$ & $3.2 \pm 2.3$ & $2.7 \pm 2.3$ \\
Rescue analgesic & $\mathrm{N} / \mathrm{A}$ & & \\
intake (tablets) & & & \\
\hline
\end{tabular}

${ }^{*} P=0.0001$ compared to acetaminophen plus codeine; ${ }^{*} P=0.0005$ compared with acetaminophen plus codeine. CR Controlled-release; N/A Not available

Both categorical and VAS pain scores measured daily were significantly lower during CR codeine weeks one to four and weeks five to eight compared with the acetaminophen plus codeine phase (Figure 1, Table 5). There was an improvement in pain scores between CR codeine weeks one to four and weeks five to eight, although the difference was not statistically significant.

There were significantly fewer rescue acetaminophen tablets taken during CR codeine weeks five to eight compared with CR codeine weeks 1 to $4(\mathrm{P}=0.0050)$ (Table 5).

Patients and investigators rated acceptability significantly higher for both CR codeine phases compared with acetaminophen plus codeine $(\mathrm{P}=0.0001)$. There were no differences between CR codeine at week 4 and week 8 .

In all cases, numerically lower (better) PDI scores were attained during the $\mathrm{CR}$ codeine periods compared with the acetaminophen plus codeine phase (Table 5). For all categories, differences between CR codeine week 4 and 8 were not statistically significant. Significant improvement from the acetaminophen plus codeine phase to CR codeine weeks 4 and 8 was observed for family/home responsibilities $(\mathrm{P}=0.0001$, $\mathrm{P}=0.0008)$, recreation $(\mathrm{P}=0.0001, \mathrm{P}=0.0049)$, social activity $(\mathrm{P}=0.0004, \mathrm{P}=0.0003)$ and occupation $(\mathrm{P}=0.0086, \mathrm{P}=0.0094)$.
TABLE 6

Adverse events

\begin{tabular}{lccc}
\hline & $\begin{array}{c}\text { Acetaminophen } \\
\text { plus codeine } \\
\text { (number of } \\
\text { patients) }\end{array}$ & $\begin{array}{c}\text { CR codeine } \\
\text { month 1 } \\
\text { (weeks 1-4) } \\
\text { (number of } \\
\text { patients) }\end{array}$ & $\begin{array}{c}\text { CR codeine } \\
\text { month 2 } \\
\text { (weeks 5-8) } \\
\text { (number of } \\
\text { patients) }\end{array}$ \\
\hline Constipation & 36 & 31 & 32 \\
Nausea & 12 & 6 & 7 \\
Somnolence & 2 & 12 & 6 \\
Dizziness & 3 & 10 & 4 \\
Dyspepsia & 3 & 6 & 1 \\
Overall & 45 & 59 & 47 \\
\hline
\end{tabular}

${ }^{\star}$ Events experienced by five or more patients. CR Controlled-release

At the end of each phase, patients rated the degree to which their sleep was disturbed by pain. For all items, there was a rank ordering of pain and sleep scores, where CR codeine week 4 scores were lower than CR codeine week 8 scores, which were lower than acetaminophen plus codeine. For each of these items, CR codeine week 8 was superior to acetaminophen plus codeine $(\mathrm{P}<0.005)$ and $C R$ codeine week 4 was superior to acetaminophen plus codeine, with the exception of 'difficulty falling asleep' ( $\mathrm{P}=0.0519)$. Although pain and sleep scores on CR codeine were lower in week 4 compared with week 8 , the difference was not statistically significant $(\mathrm{P}>0.345)$.

The number of incidences for the most common adverse events, for all patients enrolled, are shown in Table 6. During the eight weeks of treatment, only seven patients discontinued CR codeine due to adverse events. Serious adverse events (SAE) were reported for two patients. One patient experienced renal colic and the other patient had a urinary tract and yeast infection. Neither patient was withdrawn because of the SAE, and neither SAE was deemed related to the study medication by the investigators.

Forty-five patients went on to long term use after the end of the prospective study period and continued for an average of three months.

\section{DISCUSSION}

The objective of this study was to evaluate the clinical utility of the guidelines for the conversion of patients from a combination analgesic preparation of acetaminophen $300 \mathrm{mg}$ plus codeine $30 \mathrm{mg}$ administered every $4 \mathrm{~h}$ to $6 \mathrm{~h}$ to CR codeine administered every $12 \mathrm{~h}$.

Other comparative studies using CR codeine and acetaminophen plus codeine resulted in equianalgesic doses of $150 \mathrm{mg}$ CR codeine every $12 \mathrm{~h}$ and acetaminophen $600 \mathrm{mg}$ plus codeine 60 mg every 6 h $(300 \mathrm{mg}$ codeine base versus $240 \mathrm{mg}$ codeine phosphate containing $180 \mathrm{mg}$ of codeine base per day, respectively) in cancer and noncancer patients $(10,11)$. In this study, patients started CR codeine at a dose that was $50 \%$ of that calculated as equianalgesic to their baseline acetaminophen plus codeine dose and had their first dose increase approximately eight days later. By the end of the first month, patients had been titrated on CR codeine to a dose that was equivalent to their calculated equianalgesic dose, based on their baseline acetaminophen plus codeine dose. During the 
two-week prospective period on acetaminophen plus codeine in this study, patients took a mean of $8.3 \pm 3.3$ tablets per day, which contained approximately $180 \mathrm{mg}$ of codeine base. During CR codeine months 1 and 2, the average daily codeine intakes were approximately $296 \mathrm{mg}$ and $390 \mathrm{mg}$, respectively. These doses of codeine are approximately one and a half to two times greater than that received from the acetaminophen plus codeine during the two week prospective period, and fall within the estimated equianalgesic dose range. This supports the view that the acetaminophen component of acetaminophencodeine phosphate combinations may contribute up to $50 \%$ or more of the analgesic effect $(10,19-23)$.

Only $6 \%$ of patients dropped out due to adverse events during the eight weeks of treatment with CR codeine in this study. This is lower than in previous studies of much shorter duration (five to seven days) in which $15 \%$ of chronic noncancer pain patients (11), 24\% of chronic low back pain patients (16) and $9 \%$ of cancer pain patients (14) withdrew due to adverse events. The lower initial dose and gradual titration used in the present study may explain why fewer patients withdrew due to adverse events. However, in another four week trial in which patients with osteoarthritis were initiated on a dose of $50 \mathrm{mg}$ CR codeine every $12 \mathrm{~h}$, and titrated at the same rate as the present study, the dropout rate due to adverse events was substantially higher (30\%) (15).

Approximately $7 \%$ to $10 \%$ of the Caucasian population is designated as poor metabolizers of codeine due to a genetic polymorphism of cytochrome P450 2D6. Poor metabolizers may receive less analgesia with the same degree of side effects from codeine (24). Patients enrolled in this study were not prescreened for their ability to metabolize codeine. It is possible that the $10 \%$ of patients who dropped out of this study due to side effects or lack of efficacy may be accounted for by the percentage of poor metabolisers found in the general population.

It has been suggested that there is a ceiling effect to codeine analgesia above which adverse effects tend to increase disproportionately to pain relief (25). According to the Canadian Pain Society, there is no pharmacological rationale for a ceiling dose for opioids (26). Although patients who require doses above $800 \mathrm{mg}$ of codeine daily may be better managed on a lower dose of a more potent opioid (27). If patients in this study were experiencing a ceiling effect to the pain relief provided by CR codeine, one would expect to see an increase in the adverse events reported between the first and second month of treatment along with the increase in dose; however, this was not the case.

The most common adverse events were typical opioid-related adverse events, including constipation, nausea, somnolence and dizziness. Although the incidence of somnolence and dizziness was higher for CR codeine, the incidence of nausea was twice as high for acetaminophen plus codeine. Fewer patients withdrew due to adverse events during CR codeine treatment, suggesting that the events experienced during this phase were less significant than during acetaminophen plus codeine treatment. It should also be noted that acceptability ratings by both patients and investigators were significantly higher for CR codeine than acetaminophen plus codeine, indicating that these adverse events for the CR codeine treated patients were well tolerated. The high acceptability ratings may also be due to the more stable analgesia produced by the CR formulation, leading to less interrupted sleep.

The target population for this study was patients with chronic noncancer pain of mild or moderate severity; however, the pain scores at the start of the study were high, in the order of $60 \mathrm{~mm}$ on a $100 \mathrm{~mm}$ VAS scale and 2.8 on a scale of 0 to 4 , a score very close to severe (3.0). In fact, $70 \%$ of the patients rated their pain as severe or excruciating. The pain scores observed did not differ markedly from other studies examining chronic noncancer pain $(11,16)$.

The majority of patients (83.2\%) increased their dose of CR codeine during the 8 -week treatment period and $98.7 \%$ of these patients cited pain as the reason. Although it is possible that the patients' pain increased over the study period, it is unlikely, considering that the patient population had chronic pain for at least three months before the study. Other longterm studies of noncancer pain patients have shown that narcotic doses increased in only $13 \%$ of patients (13 of 99) during approximately seven months of treatment (28) and increases in dose due to exacerbation of pain were brief and the patients pain usually returned to a stable baseline (29). The dose increases in this study were therefore more likely a result of the patients optimizing their pain control, and since there was not a commensurate increase in adverse events, it suggests that the dose of codeine reached was not at the analgesic ceiling.

Although the dose of CR codeine increased from month 1 to month 2 in this study, the patients pain was significantly less than during the acetaminophen plus codeine treatment, suggesting that as needed dosing in the treatment of chronic pain does not provide maximum pain relief. This may have been due to the short duration (two weeks) of acetaminophen plus codeine treatment, although one week was deemed to be an acceptable titration period in previous studies (11) and 64\% of the patients completing the study had been taking acetaminophen plus codeine before the study. The improvements in pain scores and disability scores during the two months on CR codeine suggest that the dosing guidelines used in this study are appropriate for conversion of patients from acetaminophen plus codeine to CR codeine.

The higher acceptability ratings for CR codeine expressed by patients may be due to the eliminations of fluctuations in pain found over the day that occur when patients are treated with short-acting analgesics (16). The focus of treatment with short-acting analgesics tends to be pain or pain-related behaviours. Also the administration of immediate-release formulations leads to higher peak plasma concentrations compared with controlled-release formulations. This may result in a greater likelihood of adverse events and reluctance of patients to use larger doses. The benefit of time-contingent dosing is well accepted in the management of cancer pain and there is growing evidence, including the results of this study, that it is desirable in treating chronic noncancer pain $(28,29)$.

\section{CONCLUSION}

$\mathrm{CR}$ codeine is an effective, well-tolerated analgesic for the long term treatment of moderately severe chronic noncancer pain. Compared with the initial baseline period, during which patients were treated with acetaminophen plus codeine, CR codeine treatment resulted in significantly lower pain, and 
greater acceptability of treatment and improvement of function with a similar adverse event profile. The recommended guidelines for conversion of patients from acetaminophen plus codeine to CR codeine are: patients taking four to six tablets of acetaminophen plus codeine/day should initially transfer to 50 mg CR codeine every $12 \mathrm{~h}$, seven to nine tablets to $100 \mathrm{mg}$ every $12 \mathrm{~h}, 10$ to 12 tablets to $150 \mathrm{mg}$ every $12 \mathrm{~h}$ and more than 12 tablets to $200 \mathrm{mg}$ every $12 \mathrm{~h}$, followed by upward titration of the dose according to the patient's clinical response. These guidelines resulted in a safe and effective conversion of patients receiving acetaminophen plus codeine as needed to CR codeine every $12 \mathrm{~h}$.

ACKNOWLEDGEMENTS: The authors are grateful to the following clinicians for enrolment of patients in this study: Dr Ian Clarke (University of Calgary) and Dr Alan Sandler (University of Toronto). This study was sponsored by Purdue Pharma (Canada)

\section{REFERENCES}

1. Walsh TD, Saunders CM. Oral morphine for relief of chronic pain from cancer. New Engl J Med 1981;305:1417-8.

2. Thirlwell MP, Sloan PA, Maroun JA, et al. Pharmacokinetics and clinical efficacy of oral morphine solution and controlled-release morphine tablets in cancer patients. Cancer 1989;63:2275-83.

3. Goughnour BR, Arkinstall WW, Stewart JH. Analgesic response to single and multiple doses of controlled-release morphine tablets and morphine oral solution in cancer patients. Cancer 1989;63:2294-7.

4. Bruera E, Belzile M, Pituskin E, et al. A randomized, double-blind crossover trial comparing safety and efficacy of oral controlledreleased oxycodone with controlled-release morphine in patients with cancer pain. J Clin Oncol 1998;16:3222-9.

5. Hagen NA, Babul N. Comparative clinical efficacy and safety of a novel controlled release oxycodone formulation and controlledrelease hydromorphone in cancer pain. Cancer 1997;79;1428-37.

6. Watson CP, Babul N. Efficacy of oxycodone is neuropathic pain: A randomized trial in postherpetic neuralgia. Neurology 1998;50:1837-41.

7. Hays H, Hagen N, Thirlwell M, et al. Comparative clinical efficacy and safety of immediate release and controlled release hydromorphone for chronic severe cancer pain. Cancer 1994;74:1808-16.

8. Health and Welfare Canada. Cancer Pain: A monograph on the management of cancer pain. (Catalogue Number H42-2/5-1984E). Ottawa: Department of National Health and Welfare, 1984.

9. Band CJ, Band PR, Deschamps M, Besner JG, Coldman AJ. Human pharmacokinetic study of immediate-release (codeine phosphate) and sustained-release (Codeine Contin) codeine. J Clin Pharmacol 1994;34:938-43.

10. Chary S, Goughnour BR, Moulin DE, Thorpe WR, Harsanyi Z, Darke AC. The dose-response relationship of controlled-release codeine (Codeine Contin) in chronic cancer pain. J Pain Symptom Manage 1994;9:363-71.
11. Arkinstall W, Sandler A, Goughnour B, Babul N, Harsanyi Z, Darke AC. Efficacy of controlled-release codeine in chronic nonmalignant pain: A randomized, placebo-controlled clinical trial. Pain 1995;62:169-78.

12. Fored CM, Ejerblad E, Lindblad P, et al. Acetaminophen, aspirin, and chronic renal failure. N Engl J Med 2001;345:1801-8.

13. Bolesta S, Haber SL. Hepatotoxicity associated with chronic acetaminophen administration in patients without risk factors. Ann Pharmacother 2002;36;331-3.

14. Dhaliwal H, Sloan P, Arkinstall W, et al. Randomized evaluation of controlled-release codeine and placebo in chronic cancer pain. J Pain Symptom Manage 1995;10:612-23.

15. Peloso P, Bellamy N, Bensen W, et al. Double blind randomized placebo control trial of controlled release codeine in the treatment of osteoarthritis of the hip or knee. J Rheumatol 2000:27;764-71.

16. Hale ME, Speight KL, Harsanyi Z, et al. Efficacy of 12 hourly controlled-release codeine compared with as required dosing of acetaminophen plus codeine in patients with chronic low back pain. Pain Res Manage 1997;2:33-8.

17. Pollard CA. Preliminary validity study of the Pain Disability Index. Percept Mot Skills 1984;59:974.

18. Tait RC, Chibnall JT, Krause S. The Pain Disability Index: Psychometric properties. Pain 1990;40:171-82.

19. Beaver WT. Aspirin and acetaminophen as constituents of analgesic combinations. Arch Intern Med 1981;141:293-300.

20. Gertzbein SD, Tile M, McMurty RY, et al. Analysis of the analgesic efficacy of acetaminophen $1000 \mathrm{mg}$, codeine phosphate $60 \mathrm{mg}$, and the combination of acetaminophen $1000 \mathrm{mg}$ and codeine phosphate $60 \mathrm{mg}$ in the relief of postoperative pain. Pharmacotherapy 1986;6:104-7.

21. Wiffen P. An evidence base for WHO "essential analgesics". IASP Pain - Clinical Updates 2000;8:1-4.

22. De Craen AJ, Di Giulio G, Lampe-Schoenmaeckers JE, Kessels AG, Kleijnen J. Analgesic efficacy and safety of paracetamol-codeine combinations versus paracetamol alone: A systemic review. BMJ 1996;313:321-5.

23. Moore A, Collins S, Carroll D, McQuay H. Paracetamol with and without codeine in acute pain: A quantitative systematic review. Pain 1997;70:193-201.

24. Eckhardt K, Li S, Ammon S, Schanzle G, Mikus G, Eichelbaum M. Same incidence of adverse drug events after codeine administration irrespective of the genetically determined differences in morphine formation. Pain 1998;76:27-33.

25. Cancer Pain Relief, 2nd ed. Geneva: World Health Organization, 1996.

26. Canadian Pain Society Task Force. Use of opioid analgesics for the treatment of chronic non-cancer pain - a consensus statement and guidelines from the Canadian Pain Society. Pain Res Manage 1998;3:197-208.

27. Jovey RD. Opioid analgesics. In: Jovey RD, ed. Managing pain: The Canadian healthcare professional's reference. Toronto: Toronto Healthcare\& Financial Publishing, 2002:47-61.

28. Zenz M, Strumpf M, Tryba M. Long-term oral opioid therapy in patients with chronic nonmalignant pain. J Pain Symptom Manage 1992;7:69-77.

29. Portenoy RK, Foley KM. Chronic use of opioid analgesics in nonmalignant pain: Report of 38 cases. Pain 1986;25:171-86.

30. Codeine Contin. Compendium of Pharmaceuticals and Specialties. 36 ed. Ottawa: Canadian Pharmacists Association, 2001:331-2. 


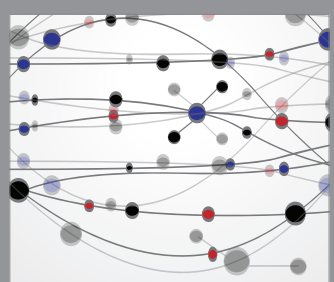

The Scientific World Journal
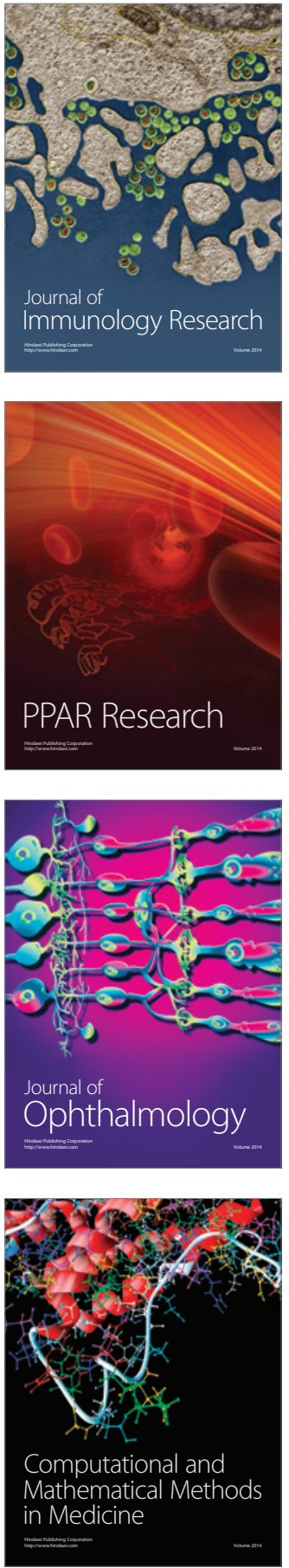

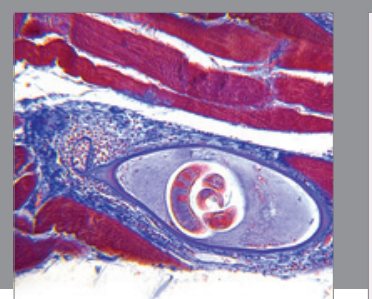

Gastroenterology Research and Practice

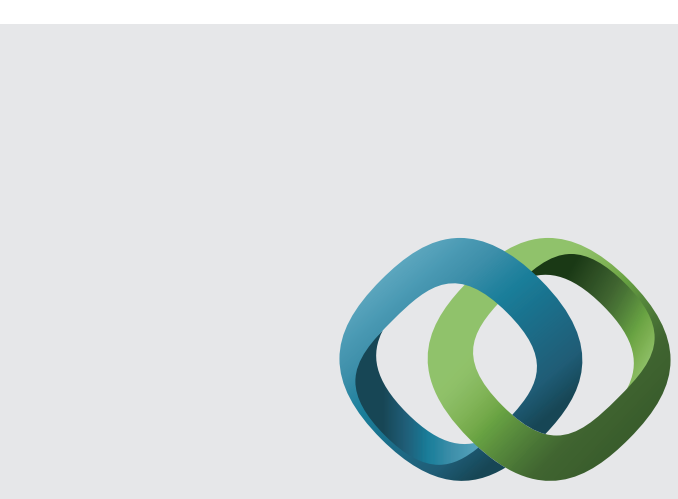

\section{Hindawi}

Submit your manuscripts at

http://www.hindawi.com
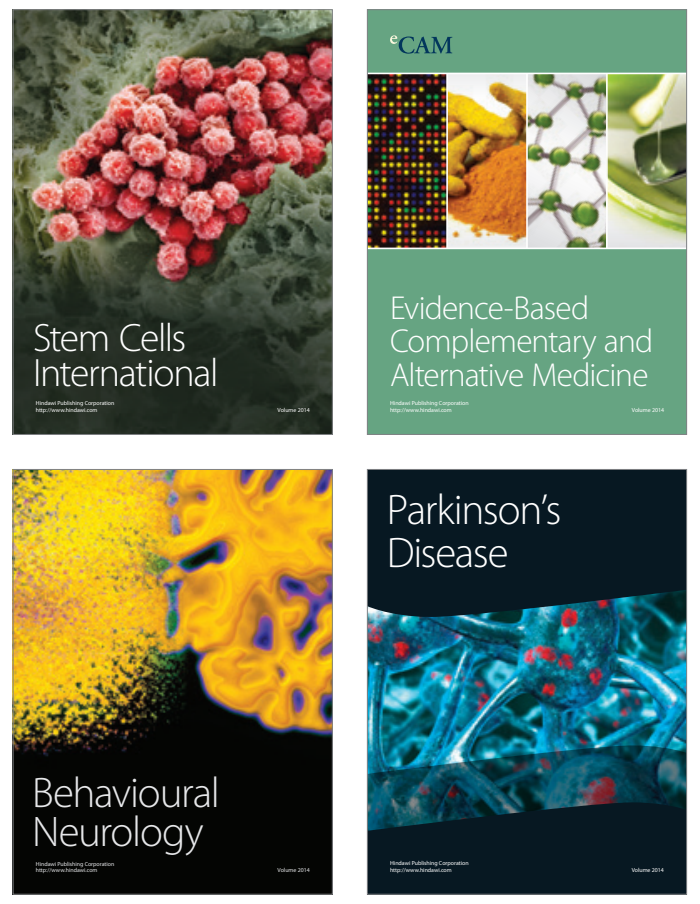
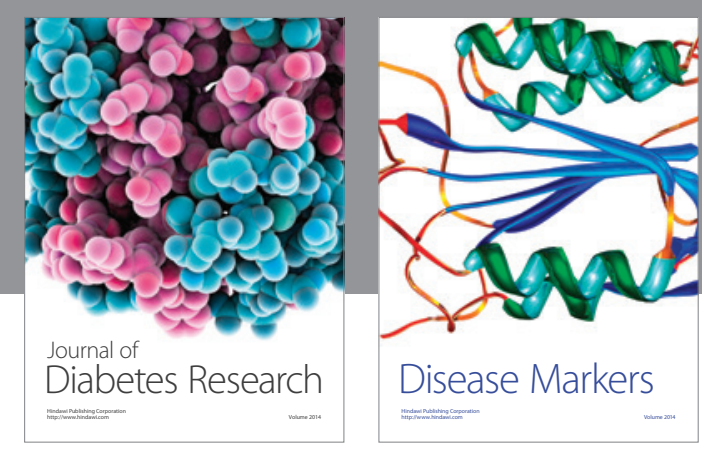

Disease Markers
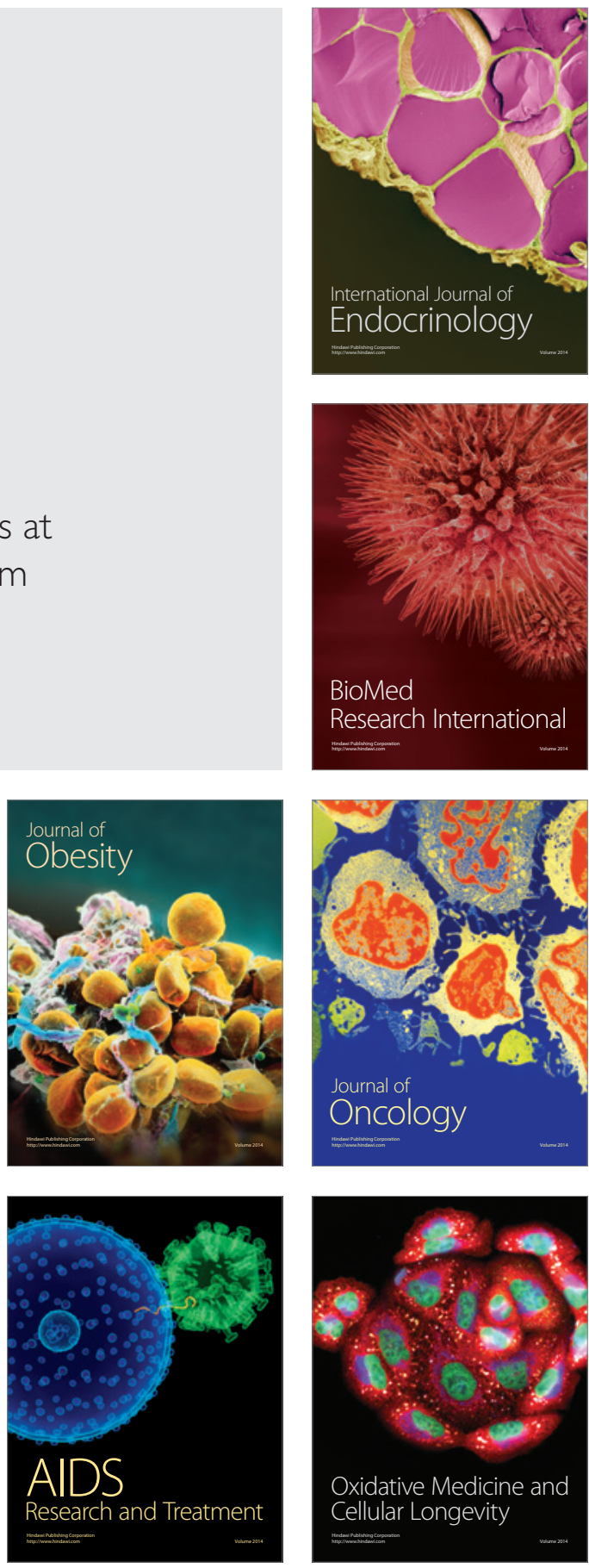